\title{
Using Startle Eye Blink to Measure the Affective Component of Antigay Bias
}

\author{
Amanda L. Mahaffey, Angela Bryan, and Kent E. Hutchison \\ University of Colorado
}

\begin{abstract}
The underlying motivations of antigay attitudes are not fully understood. One component of antigay bias in particular, the affective component, has not been thoroughly investigated because of the difficulty of accurately assessing affective responses. We investigated the potential for physiologically measuring this affective component, which we describe as homophobia, specifically using startle eye blink methodology. Two studies $(n=158$ heterosexual men over two studies) were conducted in which participants' responses to paper-and-pencil measures of homophobia were compared with their startle magnitude while viewing nude or seminude photographic stimuli of individual men and individual women (Study 1), and gay couples, lesbian couples, and heterosexual couples (Study 2). The results of Studies 1 and 2 clearly established a link between negative attitudes toward homosexual individuals and a negative physiological reaction toward viewing nude men and gay couples. In addition, erotophobia was found to interact with homophobia in predicting this affective response.
\end{abstract}

Antigay bias often is described as one of the last remaining socially acceptable prejudices. However, it poses a serious risk to its targets-homosexual individuals. Research in this area has shown that homosexual survivors of hate crimes show more signs of psychological distress (e.g., depression, stress, and anger) than do homosexual survivors of comparable non-bias-motivated crimes (Herek, Gillis, \& Cogan, 1999).

Like institutional racism and sexism, heterosexism pervades societal customs and institutions. It operates through a dual process of invisibility and attack. Homosexuality usually remains culturally invisible; when individuals who engage in homosexual behavior or who are identified as homosexual become visible, they are subject to attack by society. (Herek, no page available; obtained from the Internet, 2001)

There has been some debate through the years over the definition and even the name of the attitude generally described as "homophobia" (for a complete review, see Herek, 2000 or Adams, Wright, \& Lohr, 1996). For the purposes of this article, we were specifically interested in the affective component of antigay bias, characterized by an irrational fear of or disgust regarding homosexual individuals or a fear of being in close quarters with a homosexual individual. The affective component we are interested in is actually most closely aligned with

Requests for reprints should be sent to Amanda L. Mahaffey, Department of Psychology, UCB 345, University of Colorado, Boulder, CO, 80309-0345. E-mail: amanda@psych.colorado.edu
Weinberg's (1973) original definition of the phenomenon of antigay bias, which he called homophobia. Thus, for the purposes of this article, we will use Weinberg's terminology.

Homosexual individuals are at serious risk for hate crimes being perpetrated against them. In one study in California, more than one fourth of the men and nearly one fifth of the women surveyed had been the victim of a crime or attempted crime based on their sexual orientation at some time in their life (Herek et al., 1999). The prevalence of reported crimes is consistent with a study of 500 heterosexual adults in the San Francisco area in which half of the men sampled had engaged in some form of aggression toward homosexual individuals, and one third of those who had not committed any such acts reported that they would assault or harass a "homosexual who made a pass at them" (Franklin, 1998).

Despite convincing evidence of crime motivated by antigay bias, the underlying motivations of such attitudes are not fully understood. Van de Ven, Bornholt, and Bailey (1996) suggested a three-part model of antigay bias consisting of cognitive, affective, and behavioral components. The cognitive component and, to a lesser degree, the behavioral component have been the focus of the majority of studies. Participants tend to willingly self-report unsupportive social and political attitudes toward those who are homosexual (i.e., cognitive component), and, to some extent, participants will self-disclose previous gay-bashing experiences or display prejudice toward homosexual individuals (i.e., behavioral component). However, emotions are somewhat less tangible; homophobic individuals might not always be fully aware of the visceral reac- 
tions of threat, fear, anger, or disgust that they may experience when face-to-face with a homosexual individual. For this and other reasons, the affective component has received much less attention in the literature than the other two components and is therefore deserving of exploration.

A potential characterization of this more affective level of antigay bias was offered by Herek (1987). Herek defined four functions of sexual prejudice, three of which characterize aspects of cognitive and behavioral components (social expressive, value expressive, and experiential). The fourth, a "defensive" function, is an affective reaction whereby one is threatened by homosexuality based on fears and uncertainty about one's own sexuality or gender conformity. This fourth function is perhaps the one that distinguishes antigay bias from other forms of prejudice, and some researchers defined antigay bias based solely on this fourth function. For example, Lock and Kleis (1998) define homophobic attitudes as "defensive attempts to manage internal anxieties ... representing unresolved psychosexual issues from childhood development" (p. 73). It is also this fourth function that is associated with violence toward homosexual individuals (Herek, 1991).

One problem with accurately characterizing an affective response is the assumption that emotions can be either conscious or unconscious and thus are somewhat difficult to measure. Some researchers have opted to measure homophobia physiologically, and this approach shows promise. Shields and Harriman (1984) measured heart rate while participants viewed sexual slides. Increased heart rate was observed in some homophobic participants, yet it did not occur in any of the nonhomophobic participants. One problem with these findings is that heart rate detects physiological arousal but does not provide affective valence. Thus, this increased heart rate might reflect either a larger negative or a larger positive response. We know that homophobic participants in this study were feeling something different from nonhomophobics; however, the valence of that reaction is unclear. Adams et al. (1996) measured penile tumescence in homophobic and nonhomophobic male participants using penile plethysmography. Sexual arousal was measured while participants watched erotic videos of sex between a man and a woman, sex between two women, and sex between two men. In this study, although all participants displayed arousal to the heterosexual and lesbian films, only homophobic males displayed objective sexual arousal when viewing gay male erotic videos (Adams et al., 1996). These findings are especially intriguing because they provide support for the idea that there might be a defensive function of homophobia related to sexual identity uncertainty or confusion.

\section{PSYCHOPHYSIOLOGICAL MEASURES OF EMOTION}

Studies spanning the past two decades have confirmed that facial electromyography (EMG) can be a useful measure of attitudes in experimental settings (Cacioppo \& Petty, 1979; Cacioppo, Petty, Losch, \& Crites, 1994; Cacioppo, Petty, Losch, \& Kim, 1986; Love, 1972; Ito \& Cacioppo, 1999; Vanman, Paul, Ito, \& Miller, 1997). It is possible to determine by an individual's cheek and brow movement whether he or she is experiencing positive or negative emotion toward a stimulus (Cacioppo et al., 1994; Cacioppo et al., 1986; Ito \& Cacioppo, 1999; Vanman et al., 1997).

A prime benefit of facial EMG and other physiological measures is that they are rarely affected by social desirability (McHugo \& Lanzetta, 1983; Vanman et al., 1997). A further benefit is the notion that some emotions occur on an unconscious level. Some researchers have postulated that when this is the case, people actually may have little or no conscious awareness of their true feelings toward others and thus are unable to self-report them (Greenwald \& Banaji, 1995; Nisbett \& Wilson, 1977; Vanman et al., 1997). It is important however, not to rely solely on one source of measurement. Self-report measures are useful for ordering people in terms of level of prejudice (Wittenbrink, Judd, \& Park, 1997) so that we can then compare implicit or physiological responses between levels of prejudice.

Similar to facial EMG, startle eye blink has been used to successfully detect positive and negative affective responses (Blascovich, 2000; Lang, 1995). Recent innovative research by Amodio, Harmon-Jones, and Devine (in press) showed startle eye blink to adequately detect implicit affective race bias and to be an ideal conjunction between social psychological and neuroscientific approaches to measuring affective bias. This new evidence lays the groundwork for further studies of affective bias such as the current studies of the affective component of antigay bias.

The startle response is a primitive, defensive reflex to a brief, intense stimulus-usually a $100 \mathrm{db}, 50 \mathrm{~ms}$ burst of static. Previous studies have demonstrated that the startle response is increased or potentiated by stimuli that evoke a negative emotional response (e.g., a picture of a gunshot victim) and decreased or inhibited by stimuli that evoke a pleasant emotional response (e.g., a picture of kittens) or appetitive stimuli (e.g., nude females; c.f., Lang, 1995). The startle response is also useful in the study of fears or phobias such that objects of fears or phobias elicit greater startle in phobic or fearful people than in people who are not afraid of those objects (Hamm, Cuthbert, Globisch \& Vaitl, 1997; Sabatinelli, Bradley, Cuthbert, \& Lang, 1996). Finally, the startle response has been shown recently to accurately predict affective reactions to particular groups of people, such as those of a particular race (Amodio et al., in press). Given the nature of the affective component of antigay bias-its partially unconscious nature and its potential association with near-phobic fear and disgust toward homosexual individuals-we hypothesized that the startle response might be used as a measure of affect associated with homophobia.

We conducted two studies using self-reported homophobia to predict startle eye blink toward nude photographs of 
men, women, and couples (gay, lesbian, and heterosexual). Both studies were limited to male participants because men are more responsive to visual erotic stimuli than women are (Bailey, Gaulin, Agyei, \& Gladue, 1994; Ellis \& Symons, 1990) and because past research supports the idea that men are more inclined to show homophobic tendencies than women are (Herek \& Capitanio, 1999; Kite \& Whitley, 1998; Yang, 1998; Johnson, Brems, \& Alford-Keating, 1997; Hansen, 1982; Kunkel \& Temple, 1992; Larsen, Reed, \& Hoffman, 1980).

\section{STUDY 1}

The aim of the first study was to assess the utility of the startle response as an indirect physiological measure of affect related to homophobia. Our explicit measure of interest, the Social Distance Measure of Homophobia (Gentry, 1986), was embedded within a larger packet of filler measures, consisting of several attitude measures and demographic questions. This scale measures the social distance with which one is comfortable between oneself and a homosexual man and was developed to assess affective reactions toward homosexual men, because most measures of antigay bias focus more on the cognitive component. In essence, this measure taps the "fear of being in close quarters with a homosexual" aspect of the definition of homophobia we sought to measure. The eight items ranged from "I would be uncomfortable at a party where a homosexual man was present" to "It would bother me to live in the same house as a homosexual man." Because the focus of our line of inquiry is exclusively the affective component of antigay bias or homophobia, we determined the inclusion of such a measure of homophobia that tapped this affective reaction to be crucial.

The primary hypothesis was as follows: We suspected that physiological affective reactions to viewing nude or seminude males would depend on levels of self-reported prejudice toward homosexual men. In other words, the greater the self-reported discomfort with social contact with gay men shown by participants, the greater the expected magnitude (and thus, the more negative the emotional reaction) of the startle response.

\section{Method}

Participants. Participants were 58 undergraduate men who agreed to participate in exchange for credit for an introductory psychology class. Nine of these participants eventually were excluded from the analysis because of technical difficulties with the startle recording equipment, participants not displaying a startle response at a level above that distinguishable from random noise, or participants not completing all parts of the experimental session. The final sample included 49 participants (88\% White, $4 \%$ Hispanic/Latino, $4 \%$ Asian American, 2\% African American, and 2\% Native American) ranging in age from 18 to 27 years with a mean age of 19 years. Most reported a having a Christian Protestant affiliation or no religious affiliation, and all participants reported having exclusively heterosexual orientation according to the Kinsey scale (Kinsey, Pomeroy, \& Martin, 1948).

Materials. Materials consisted of a 12-paged paper-and-pencil questionnaire consisting of a number of attitude measures. The measure of interest was the Social Distance Measure of Homophobia (Gentry, 1986; $k=8$, Study 1 $\alpha=.93$, Study $2 \alpha=.94$ ). Participants were asked to respond to each attitude statement using a 7-point Likert-type scale with 1 being "entirely disagree" and 7 being "entirely agree". Responses to items within each scale were averaged to determine a participants' score for that measure. We also collected demographic information including age, ethnicity, religious affiliation, and degree of religiosity. Finally, we assessed sexual orientation using the Kinsey Scale, a single-item, Likert-type scale that assesses sexual orientation with entirely heterosexual at one end of the continuum and entirely homosexual at the other (Kinsey et al., 1948).

Photographic stimuli consisted of six affectively neutral (e.g., an electrical outlet) and six affectively negative (e.g., a gunshot victim) stimuli drawn from the International Affective Picture System (IAPS; Center for the Psychophysiological Study of Emotion and Attention, 1994). ${ }^{1}$ Each picture was chosen based on its published normative data for men. In addition, we used six male nude or seminude stimuli and six female nude or seminude stimuli drawn from the public domain. All nude stimuli were White so that ethnicity of the stimuli would not act as a confound.

Procedure. All procedures were reviewed and approved by a university-level internal review board (IRB). Participants each attended an individual experimental session that lasted approximately $1.5 \mathrm{hr}$. The experimenter described the study to the participant as a method of assessing feelings about pictures by observing brainwaves. The experimenter explained all questionnaires and physiological measures and answered any questions. Participants read and signed IRB-approved informed consent documents. Each participant completed all paper-and-pencil questionnaires.

Participants were then monitored for startle response via two 4-mm Ag-Ag Cl surface electrodes (Biopac Systems, Goleta, CA) placed under the left lower eyelid, $20 \mathrm{~mm}$ apart, over the orbicularis oculi muscle. In addition, a ground electrode was placed on the forehead. The skin beneath the electrodes was cleaned with an alcohol-saturated cotton swab immediately before electrode placement to lower impedance levels. The startle-eliciting stimulus was a $105 \mathrm{~dB}$ broadband noise that was $50 \mathrm{~ms}$ in duration. All auditory stimuli were administered to participants via headphones. Participants

1IAPS numbers: (negative stimuli) 3010, 3170, 9040, 9252, 9300, 9410, (neutral stimuli) 5520, 6150, 7090, 7207, 7217, 7235. 
were instructed to observe a computer screen for the presentation of the photographs. To control for the effects of habituation across trial types, the order of presentation was randomized for each participant. Participants viewed each new slide for 5,000 ms, and the startle probe occurred 4,000 ms after slide onset. This latency interval was deemed ideal for our purposes because of recent evidence by Amodio and colleagues (in press) that long-latency startle eye blink (e.g., $4,000 \mathrm{~ms}$ ) is adequate for indexing automatic affective race bias. Between each slide, the computer screen remained blank for a randomly generated variable interval, ranging from 18 to $22 \mathrm{~s}$, to clear any emotion associated with the previous image. The slide presentation was automated, and the participants were unable to modify the presentation pace. ${ }^{2}$ The EMG signal was sampled at $1,000 \mathrm{~Hz}$ and was filtered with a bandwidth of $28-500 \mathrm{~Hz}$.

\section{Results}

Startle eye blink patterns. Startle magnitude toward each of the six photographs within each of the five categories of visual stimuli was averaged within participants. Mean startle magnitude for each stimulus type followed the same general pattern found in previous research in this area (e.g., Lang, 1995). Negatively valenced stimuli elicited the largest blink magnitude $(M=.793, S D=.65)$. Neutral stimuli elicited somewhat smaller peaks $(M=.675, S D=.59)$. Nude stimuli elicited the smallest startle response, with no significantly distinguishable difference between the male nudes and female nudes, male nude $M=.645, S D=.57$, and female nude $M=.641, S D=$ .57. A within-subjects analysis of variance (ANOVA) was conducted to assess whether there were differences among the startle means. The overall test for difference was significant, $F(4,180)=7.60, p<.0001$. All possible post hoc pairwise comparisons were then examined. Male and female nudes did not elicit significantly different levels of startle, which is not surprising given evidence that startle cannot typically show fine-grained distinctions between closely related stimuli. However, both of these means were significantly lower (i.e., more positive) than the means for the negative stimuli.

Relationships between homophobia and startle eye blink. Startle magnitudes toward each of the six photographs within each of the four categories of visual stimuli were averaged within participants. To further minimize the influence of individual differences in overall startle reflex, the mean response in each category of interest (negative, nude male, and nude female) was divided by that partici-

\footnotetext{
${ }^{2}$ On a second viewing, participants were asked for their subjective emotional response to each photograph using the Self-Assessment Manikin (SAM; Lang, 1980) and equivalent Likert-type scales. These data were recorded to establish normative ratings and validity of our photographic stimuli and are not presented here. These ratings may be obtained by contacting the first author (ALM).
}

pant's mean response to neutral stimuli (c.f., Hutchison \& Swift, 1999), and these products served as the criterion variables in all regression analyses. For each type of picture (negative, female nude, male nude), a regression equation was estimated in which the Social Distance Measure of Homophobia served as the predictor, with the startle response serving as the criterion. In total, three regression equations were estimated, and two of these equations produced significant results. A significant relationship was established between the social distance homophobia measure and startle magnitude. In accord with our main hypothesis, men who expressed greater feelings of homophobia on the social distance measure showed greater startle magnitude toward nude male stimuli, $B=.31, p<.05$. In other words, homophobic men had a more negative response to looking at nude men than did less homophobic men. Interestingly, not only did more homophobic men not only tended to dislike looking at nude males but also appeared to perceive nude females less positively than did nonhomophobic males. The greater a man's feelings of homophobia, the greater his blink magnitude toward nude female stimuli, $B=.34, p<$ .05 .

\section{Study 1 Discussion}

The results of Study 1 support the hypothesized association between homophobia and startle eye blink toward pictures of nude men. Men who reported on the social distance measure that they would be uncomfortable being in close quarters with a homosexual man also exhibited this response physiologically. Interestingly, men who reported being homophobic according to the social distance measure exhibited a significantly greater startle response toward both male and female nudes than those who expressed less discomfort in the presence of a gay man. Because the acoustic startle response is an automatic reaction, it is possible that once homophobic men completed the social distance measure and were exposed to photographs of nude males, they may have generalized this feeling of discomfort such that they associated any nude photograph with this experience of a negative emotional reaction. However, this situation is unlikely because our methods were designed to control for it by adding an 18- to 22-s gap between the presentations of stimuli. Another possible explanation for this phenomenon is that some homophobic men are, in general, somewhat sexually repressed or made uncomfortable by exposure to erotic material of any type. One method of exploring this issue is to include a measure of erotophobia to assess discomfort with sexuality and sexual material (Fisher, Byrne, White, \& Kelley, 1988). This was our strategy in Study 2.

From a conceptual standpoint, it is also possible that the stimuli used in the current study were not as strong as they might have been. In this study, we exclusively used photographs of nude individuals. The striking results of Adams et al. (1996) were obtained using couples engaged in erotic ac- 
tivity. It is possible that although our photographs elicited responses toward the people in the photographs or discomfort associated with viewing a nude individual, they may not have elicited specific attitudes about sexual orientation and homosexual sexual activity.

\section{STUDY 2}

We conducted a second study to address the concerns of Study 1. Recall that in Study 1, homophobic men showed physiological discomfort while viewing all nudes-male and female. Thus, in this second study, we added a measure of Erotophobia-Erotophilia (Fisher et al., 1988) to ensure that discomfort with sexuality in general, as opposed to homosexuality specifically, was not responsible for our effects. It is important to note that we did not predict that all homophobic men are erotophobic. We simply were interested in parceling out any effects caused by erotophobia (in all participants) to be certain that our effects were not caused by discomfort with sexuality in general as opposed to discomfort with homosexuality in particular. We further examined the possibility that for those who are homophobic, greater erotophobia might exacerbate the threat effect. We hypothesized that there might be a subgroup of homophobic men (those who are also erotophobic), who experience stronger visceral reactions of fear and disgust when in contact with a gay man.

A major difference in the photographic stimuli used in Study 2 was that we used photographs of nude couples rather than of individual nudes. Our purpose in changing the stimuli to photographs of couples was to help us better distinguish between emotions toward homosexuality and emotions toward generalized sexuality. Thus, our hope was that the effect of startle toward female nudes in Study 1 was simply an artifact and that by using couples we could confirm this suggestion. If we had replicated this effect, we would have shown that it was not an artifact, and it would have weakened our main hypothesis. The hypothesis was that the explicit depiction of a male homosexual relationship would arouse more negative emotions in homophobic men than either heterosexual relationships or lesbian relationships. We believed that seeing a male couple engaging in a homosexual act would be more disturbing to homophobic men than simply seeing a solitary nude male. Because of evidence that heterosexual men show greater sexual arousal toward lesbian stimuli than heterosexual stimuli (Sakheim, Barlow, Beck, \& Abrahamson, 1985), we believed that this would translate into more positive affect, thereby inhibiting startle magnitude. Thus, in Study 2, we hypothesized that homophobic men would respond more negatively to nude gay male photographs than those low in homophobia and that this would be more true for those high in erotophobia. In addition, we hypothesized that there would not be a difference in reactions to lesbian and heterosexual stimuli on the basis of homophobia or erotophobia.

\section{Method}

Participants. Participants were 100 undergraduate men who agreed to participate in exchange for credit for an introductory psychology class. For the same reasons discussed in Study 1, startle data from 26 participants were unusable. In addition, the startle data of 2 participants were dropped because the startle means were in excess of three standard deviations above the mean. Finally, 1 participant was dropped from all analyses because of his self-reported homosexual orientation. Of the final sample of 74 participants, $86 \%$ were White, $5 \%$ were Hispanic/Latino, $3 \%$ were Asian American, $2 \%$ were African American, and $4 \%$ did not specify ethnicity. Participants ranged in age from 18 to 26 years, with a mean age of 19.4 years. Most reported having a Christian Protestant or Catholic affiliation or having no religious affiliation.

Materials. Materials were similar to Study 1. The Erotophobia-Erotophilia (Fisher et al. 1988) scale was added to the larger questionnaire, and these items were randomly intermingled with the other attitude measures. The Erotophobia-Erotophilia scale was developed by Fisher and colleagues to assess attitudes toward personally experiencing erotic activity and exposure to erotic material. Some sample items include the following: "Erotica (sexually explicit books, movies, etc.) is obviously filthy and people should not try to describe it as anything else" and "If people thought I was interested in oral sex, I would be embarrassed" $(k=21, \alpha=.86)$.

The photographic stimuli changed for Study 2 in that we used photographs of nude couples rather than of single nudes. Couples included gay males, lesbians, and heterosexuals taken from the public domain; six of each category were shown to participants. The people shown in the photographs were either nude or seminude, and each of the photographs depicted romance, foreplay, or sexual intent, but no overt sexual activity. The same six negative and six neutral photographic stimuli used in the Study 1 were used in Study 2.

Procedure. All procedures were approved by a university-level IRB, and all participants read and signed informed consent documents before the experiment. The procedures differed from Study 1 in that each participant was exposed to two separate viewing sessions within one experimental session. After filling out the questionnaires, participants viewed the negative, neutral, and nude gay male photographs presented in random order for 5,000 ms each, accompanied by the startle probe at $4,000 \mathrm{~ms}$. Participants were then offered a break before beginning the second viewing session to clear their minds and rest their eyes. Next, participants viewed the nude lesbian and nude heterosexual stimuli, as well as the repeated nude gay male stimuli, presented in random order. Each photograph was accompanied by a startle probe at 4,000 $\mathrm{ms}$ as described in Study 1. 


\section{Results}

Erotophobia was correlated with social distance, though not strongly $(r=.23, p<.05)$, suggesting that there is a relationship between the two attitudes, but that they are clearly distinct constructs.

Startle eye blink patterns. Data from each of the two viewing sessions were analyzed separately. As in the first two studies, mean startle magnitude for the photographic stimuli followed the same general pattern found in previous research in this area. Negatively valenced stimuli elicited the largest startle magnitude $(M=.876, S D=.59)$. Neutral stimuli elicited somewhat lower startle $(M=.821, S D=.55)$. Nude gay male stimuli elicited the smallest startle response in the first viewing session $(M=.708, S D=.44)$. The overall test for difference in a within-subjects ANOVA was significant, $F(2,142)=15.18, p<.0001$. Post hoc pairwise comparisons showed that reactions to nude gay male stimuli were different from reactions to both the negative and neutral stimuli categories, and there was a marginally significant difference between negatively valenced and neutral stimuli.

The mean startle magnitudes were all lower in the second viewing session compared with the first. This result is likely a combination of two factors. First, the second session consisted of all nude photographs, and our previous results show that nudes elicit the smallest startle response. Second, some habituation to the startle noise likely occurred by the second session. Mean differences are, nonetheless, in the predicted direction. Nude gay male stimuli elicited the largest startle magnitude $(M=.579, S D=.46)$, with startle toward nude heterosexual stimuli being only slightly smaller $(M=.572, S D=$ .45). Photographs of nude lesbian couples produced the smallest (most positive) startle magnitude $(M=.519, S D=$ .38). The overall test for difference in a within-subjects ANOVA was significant, $F(2,142)=4.00, p<.02$. Pairwise comparisons showed that reactions to nude lesbian stimuli were different from reactions to either of the other two relationship categories; however, nude gay male and nude heterosexual stimuli did not elicit statistically different responses.

Relationships between attitude measures and startle eye blink. Our hypotheses for Study 2 involved whether the relationship between homophobia and startle toward male couples could be accounted for by a general discomfort with sexuality. Secondarily, we wanted to assess whether a discomfort with sexuality exacerbates the relationship of homophobia to startle. To test these hypotheses, we estimated a set of regression equations in which the Social Distance Measure of Homophobia, Erotophobia, and their interaction were entered as predictors of startle response in regression equations. Following standard procedures in the testing of interactions in regression (Aiken \& West, 1991), interaction terms were computed by mean, deviating each participant's score on each variable and then multiplying these two figures to form the interaction term. The mean deviated versions of the main effect measures (erotophobia and homophobia) and their interaction then served as the three predictors in each regression equation.

The relationships of social distance, erotophobia, or their interaction to startle toward lesbian or heterosexual couples were not significant. However, a significant relationship was established between the Social Distance Homophobia measure and startle magnitude after the first presentation of gay male couples (see Table 1). In accord with our main hypothesis, men who scored higher on the social distance measure showed greater startle magnitude toward nude gay male stimuli, $B=.26 . p<.05$. Thus, we established a significant main effect relationship of homophobia to startle even after controlling for discomfort with sexual issues in general. Further, although erotophobia itself was not a significant predictor of startle magnitude, there was a significant interaction between erotophobia and social distance with regard to startle magnitude while viewing nude gay males, $B=.23, p<.05$. To probe the interaction, additional regression models were estimated to test the effect of social distance at different levels of erotophobia (see Figure 1). The coefficient for the effect of social distance on startle toward gay couples was $B=.47, p<$ .01 , at one standard deviation above the mean of erotophobia, $B=.23, p<.05$, (from original equation) at the mean of erotophobia, and $B=.04, n s$, at one standard deviation below the mean of erotophobia. Thus, for those who have positive feelings about sexuality in general (i.e., low erotophobia), their social distance status bares no relationship to their startle toward gay males, whereas for those who are uncomfortable with sexuality in general (i.e., high erotophobia), discomfort with actual social contact with homosexual men shows a strong relationship to startle response toward photographs of gay male couples.

To determine whether startle response toward a particular stimulus category (e.g., gay male couples) differed from startle toward another category (e.g., lesbian couples) dependent on social distance, we conducted further analyses to test whether the regression coefficients for the relationship of social distance to startle were different across stimulus categories (Judd, McClelland, \& Smith, 1996). A difference score was created for the difference between the startle magnitude for each pair of categories (i.e., gay male vs. lesbian stimuli,

TABLE 1

Source Table for the Relationships Between Attitudes and Startle Eye Blink Toward Images of Nude Gay Couples in Study 2

\begin{tabular}{lcccc}
\hline Predictors & $B$ & p value & $R^{2}$ & $p$ value \\
\hline Model & & & .13 & $<.05$ \\
$\quad$ Social Distance & .26 & $<.05$ & & \\
$\quad$ Erotophobia-Erotophilia & .05 & n.s. & & \\
Social Distance $\times$ Erotophobia & .23 & $<.05$ & & \\
\hline
\end{tabular}




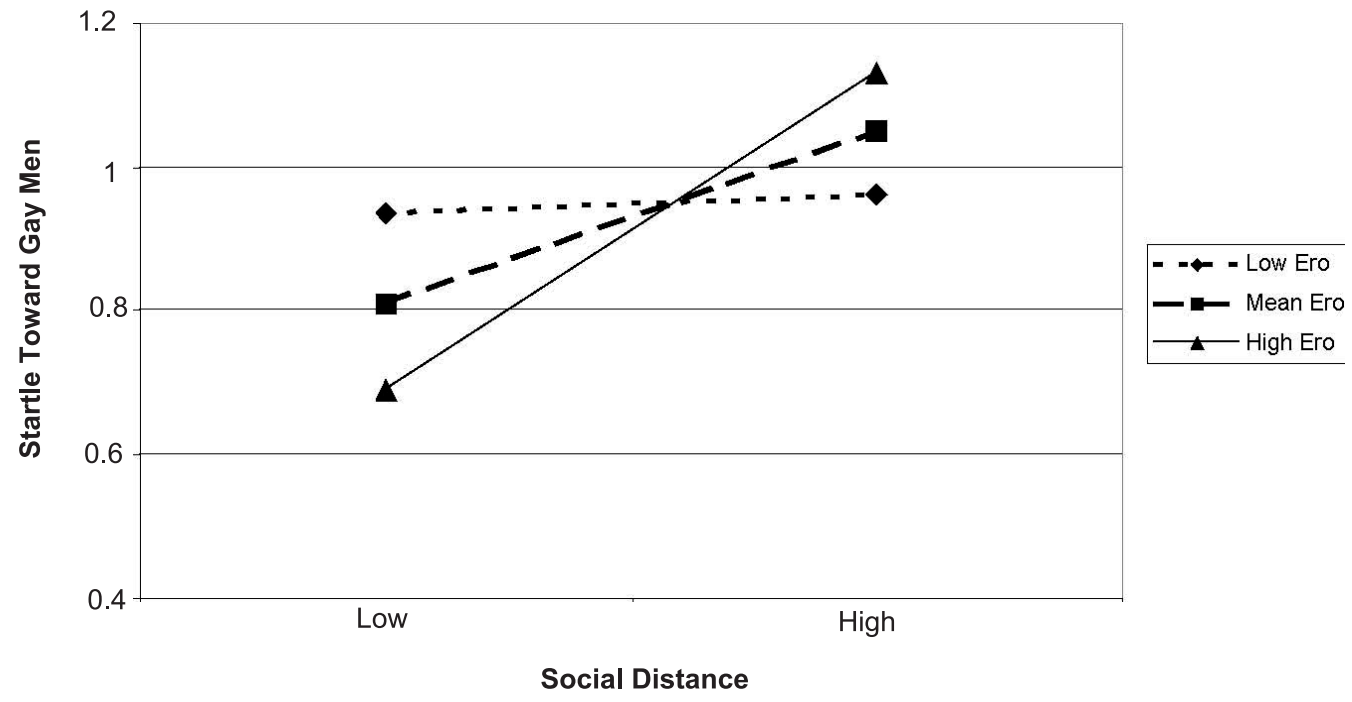

FIGURE 1 The effects of social distance on startle magnitude toward nude gay couples depending on level of erotophobia (Ero). The coefficient for the effect of social distance on startle toward gay couples was $B=.47, p<.01$ at one standard deviation above the mean of erotophobia, $B=.23, p<.05$ at the mean of erotophobia, and $B=.04, n s$ at one standard deviation below the mean of erotophobia.

gay male vs. heterosexual stimuli, gay male vs. negative stimuli, lesbian vs. heterosexual stimuli, lesbian vs. negative stimuli, and heterosexual vs. negative stimuli), then six regressions were conducted using these difference scores as criterion and social distance as the predictor in each. Thus, we tested whether the differences in startle magnitude toward each of the stimulus categories could be predicted by social distance. Three of these equations yielded significant differences. Startle toward gay male stimuli was significantly different from startle toward all other stimulus categories with regard to level of homophobia (lesbian images, $B=.39, p<$ .001 ; heterosexual images, $B=.40, p<.001$; negative images, $B=.32, p<.01)$. None of the other comparisons approached significance ( $B$ s ranged from .018 to .18). It is clear that the simple relationship between homophobia and startle toward gay male couples is genuinely different from any of the other simple regressions, and thus our main hypothesis was confirmed.

\section{GENERAL DISCUSSION}

The intent of our studies was to test whether a physiological measure was associated with the negative affective component of antigay bias, that is, homophobia. This affective component and the related defensive function have eluded empirical researchers for years because of the relative difficulty of measuring emotional responses. Given the negative emotion associated with homophobia, we chose to test a potential link between homophobia and the acoustic startle eye blink response. Acoustic startle eye blink is a reliable and widely used physiological measure of affective valence. The results of Studies 1 and 2 clearly establish a link between negative attitudes toward homosexual men and an affectively negative reaction toward viewing nude men and gay couples. It is important to note however, that although we tapped an affectively negative reaction, our studies were not designed to assess whether this affect is the result of Herek's notion of the defensive function or simply a negative affective component of the more general attitude associated with antigay bias. Our results, therefore, do not confirm or disconfirm the presence of a defensive function. Nevertheless, these findings are important, because they are one of the first demonstrations of a negatively valenced affective physiological response of homophobic men toward nude males and nude male couples.

Our effects do not appear to be the result of a main effect of discomfort with sexuality in general (i.e., erotophobia), because homophobia exhibited a significant relationship to startle magnitude, even after controlling for erotophobia. Interestingly, erotophobia also interacted with homophobia to exacerbate startle response. For those who are very comfortable with all aspects of sexuality, social distance appears to have insulated them from a negative affective reaction toward gay male couples. In other words, homophobic men who are comfortable with sexuality in general did not appear to experience a negative physiological reaction to viewing gay male couples. Participants who showed discomfort with all aspects of sexuality experienced the threat of actual social contact with a gay man strongly related to their experience of a negative affective reaction toward the sight of gay couples.

The findings of our studies lay an exciting groundwork for a range of future work in the domain of psychophysiological 
investigations of homophobia. One future direction we are pursuing includes the use of short-lead startle eye blink (i.e., presenting the startle noise at around $800 \mathrm{~ms}$ as opposed to $4,000 \mathrm{~ms}$ after stimulus onset). This approach will allow us to assess whether the ability to cognitively consider one's feelings toward the stimuli (as can be done with a 4,000-ms presentation) influences startle response toward those stimuli. It is hoped that a short-lead presentation of the startle noise will capture the unconscious and potentially implicit affective response unaffected by cognitive factors. Another avenue to pursue is the investigation of our effects with both genders. Historically, women display less antigay bias than men. It would be interesting to know whether women's automatic reactions are also more positive and whether their self-reports of homophobia are correlated with their physiological responses.

Our findings are limited in ways similar to most basic social psychological, and certainly most psychophysiological, research. First, the generalizability of our findings is limited by our use of a college population. Another limitation was our inability to preselect participants based on their level of homophobia. Although participants spanned the full range of social distance scores, the mean response was one of relatively low homophobia. Our design would have been much stronger if we had had the ability to preselect people at each end of the continuum (i.e., those high in homophobia and those low in homophobia) to participate.

Our studies are the first to establish a relationship between startle eye blink and homophobic attitudes. Thus, one contribution of this work is the establishment of startle eye blink as an additional psychophysiological measure that might be used in other studies of attitudes. Our work also reinforces the utility of startle eye blink as a measure of affect in response to a stimulus. The relatively nascent field of social neuroscience, a subfield of psychophysiology, is rapidly accumulating a body of research relating psychophysiological measures to social attitudes (Ito \& Cacioppo, 1999). Similarly, social psychologists are becoming increasingly interested in attitudes that are automatic or implicit in nature (Blair, 2001), and these attitudes are difficult to measure using conventional methods. Psychophysiological methods may prove to be valuable tools in research that seeks to quantify these elusive and, in the case of homophobia, potentially dangerous aspects of human nature.

\section{ACKNOWLEDGMENTS}

The authors thank Tiffany A. Ito and Charles M. Judd for providing invaluable and detailed suggestions for improvement on earlier drafts of this article. The authors also thank Suzie Reiss, Kim Chestnut, Kim Gallagher, Erica Sandman, and Alison Aylward for their assistance in data collection.

\section{REFERENCES}

Adams, H. E., Wright, L. W., \& Lohr, B. A. (1996). Is homophobia associated with homosexual arousal? Journal of Abnormal Psychology, 105(3), 440-445.

Aiken, L. S., \& West, S. G. (1991). Multiple regression: Testing and interpreting interactions. Newbury Park, CA: Sage.

Amodio, D. M., Harmon-Jones, E., \& Devine, P. G. (2003). Individual differences in the activation and control of affective race bias as assessed by startle eyeblink responses and self-report. Journal of Personality and Social Psychology, 84, 738-753.

Bailey, J. M., Gaulin, S., Agyei, Y., \& Gladue, B. A. (1994). Effects of gender and sexual orientation on evolutionarily relevant aspects of human mating psychology. Journal of Personality and Social Psychology, 66, 1081-1093.

Blair, I. V. (2001). Implicit stereotypes and prejudice. In G. B. Moskowitz (Ed.), Cognitive social psychology: The Princeton symposium on the legacy and future of social cognition (pp. 359-374). Mahwah, NJ: Lawrence Erlbaum Associates, Inc.

Blascovich, J. (2000). Psychophysiological methods. In H. T. Reis and C. M. Judd (Eds.) Handbook of research methods in social and personality psychology (pp. 117-137). Cambridge, UK: Cambridge University Press.

Cacioppo; J. T., \& Petty, R. E. (1979). Attitudes and cognitive response: An electrophysiological approach. Journal of Personality and Social Psychology, 37, 2181-2199.

Cacioppo, J. T., Petty, R. E., Losch, M. E., \& Crites, S. L. (1994) Psychophysiological approaches to attitudes: Detecting affective dispositions when people won't say, can't say, or don't even know. In S. Sharitt \& T.C. Brock (Eds.), Persuasion: Psychological insights and perspectives (pp. 43-69). Boston: Allyn \& Bacon.

Cacioppo, J. T., Petty, R. E., Losch, M. E., \& Kim, H. S. (1986). Electromyographic activity over facial muscle regions can differentiate the valence and intensity of affective reactions. Journal of Personality and Social Psychology, 50, 260-268.

Center for the Psychophysiological Study of Emotion and Attention. (1994). The International Affective Picture System [photographic slides]. Gainesville, FL: Center for Research in Psychophysiology, University of Florida.

Ellis, B. J., \& Symons, D. (1990). Sex differences in sexual fantasy: An evolutionary psychological approach. Journal of Sex Research, 27, 527-555.

Fisher, W. A., Byrne, D., White, L. A., Kelley, K. (1988). Erotophobia-erotophilia as a dimension of personality, Journal of Sex Research, 25, 123-151.

Franklin, K. (1998). Unassuming motivations: Contextualizing the narratives of antigay assailants. In G. M. Herek, (Ed.), Stigma and sexual orientation: Understanding prejudice against lesbians, gay men, and bisexuals (pp. 1-23). Newbury Park, CA: Sage.

Gentry, G. S. (1986). Development of scales measuring social distance toward male and female homosexuals. Journal of Homosexuality, 13, 75-82.

Greenwald, A. G., \& Banaji, M. R. (1995). Implicit social cognition: Attitudes, self-esteem, and stereotypes. Psychological Review, 102, 4-27.

Hamm, A. O., Cuthbert, B. N., Globisch, J., \& Vaitl, D. (1997). Fear and the startle reflex: Blink modulation and autonomic response patterns in animal and mutilation fearful subjects. Psychophysiology, 34, 97-107.

Hansen, G. L. (1982). Androgyny, sex-role orientation, and homosexism. Journal of Psychology, 112, 39-40.

Herek, G. M. (n.d.). Definitions: Homophobia, Heterosexism, and Sexual Prejudice. Retrieved October 31, 2004 from http://psychology.ucdavis.edu/rainbow/html/prej_defn.html.

Herek, G. M. (1987). Can functions be measured? A new perspective on the functional approach to attitudes. Social Psychology Quarterly, 50, 285-303.

Herek, G. M. (1991). Stigma, prejudice, and violence against lesbians and gay men. In J. C. Gonsiorek \& J. D. Weinrich (Eds.), Homosexuality: Research implications for public policy (pp. 60-80). Newbury Park, CA: Sage. 
Herek, G. M., \& Capitanio, J .P. (1999). Sex differences in how heterosexuals think about lesbians and gay men: Evidence form survey context effects. Journal of Sex Research, 36, 348-360.

Herek, G. M., Gillis, J. R., \& Cogan, J. (1999). Psychological sequelae of hate crime victimization among lesbian, gay, and bisexual adults. Journal of Consulting and Clinical Psychology, 67, 945-951.

Herek, G. M. (2000). The psychology of sexual prejudice. Current Directions in Psychological Science, 9, 19-22.

Hutchison, K. E. \& Swift, R. (1999). Effect of d-Amphetamine on prepulse inhibition of the startle reflex in humans. Psychopharmacology, 143, 394-400.

Ito, T. A., \& Cacioppo, J. T. (1999). Affect and attitudes. In J. P Forgas (Ed.), The handbook of affect and social cognition. Mahwah, NJ: Lawrence Elrbaum Associates, Inc.

Johnson, M. E., Brems, C., \& Alford-Keating, P. (1997). Personality correlates of homophobia. Journal of Homosexuality, 34, 57-69.

Judd, C. M., McClelland, G. H., \& Smith, E. R. (1996). Testing treatment by covariate interactions when treatment varies within subjects. Psychological Methods, 1, 366-378.

Kinsey, A. C., Pomeroy, W. B., \& Martin, C.E. (1948). Sexual behavior in the human male. Philadelphia: Saunders.

Kite, M. E., \& Whitley, B. E., Jr. (1998). Do heterosexual women and men differ in their attitude toward homosexuality? A conceptual and methodological analysis. In G. M. Herek (Ed.), Stigma and sexual orientation: Understanding prejudice against lesbians, gay men, and bisexuals (pp. 1-23). Newbury Park, CA: Sage.

Kunkel, L. E., \& Temple, L. L. (1992). Attitudes towards AIDS and homosexuals: Gender, marital status, and religion. Journal of Applied Social Psychology, 22, 1030-1040.

Lang, P. J. (1980). Behavioral treatment and bio-behavioral assessment: Computer applications. In J. B. Sidowski, J. H. Johnson, \& T. A. Williams (Eds.), Technology in mental health care delivery systems (pp. 119-137). Norwood, NJ: Ablex.

Lang, P. J. (1995). The emotion probe: Studies of motivation and attention. American Psychologist, 50, 372-385.

Larsen, K. S., Reed, M., \& Hoffman, S. (1980). Attitudes of heterosexuals toward homosexuality: A Likert-type scale and construct validity. Journal of Sex Research, 16, 245-257.
Lock, J., \& Kleis, B. (1998). Origins of homophobia in males: Psychosexual vulnerabilities and defense development. American Journal of Psychotherapy, 52, 425-436.

Love, R. E. (1972). Unobtrusive measurement of cognitive reactions to persuasive communication. Unpublished doctorial dissertation, Ohio State University, Columbus.

McHugo, G. J., \& Lanzetta, J. T. (1983). Methodological decision in social psychophysiology. In

J. T. Cacioppo \& R. E. Petty (Eds.), Social psychophysiology: A sourcebook (pp. 630-665). New York: Guilford.

Nisbett, R. E., \& Wilson, T. D. (1977). Telling more than we can know: Verbal reports on mental processes. Psychological Review, 84, 231-259.

Sabatinelli, D., Bradley, M. M., Cuthbert, B. N., \& Lang, P. J. (1996). Wait and see: Aversion and activation in anticipation and perception. Psychophysiology, 33(Suppl. 1), S72.

Sakheim, D. K., Barlow, D. H., Beck, J. G., \& Abrahamson, D. J. (1985). A comparison of male heterosexual and homosexual patterns of sexual arousal. Journal of Sex Research, 21, 183-198.

Shields, S. A., \& Harriman, R. E. (1984). Fear of male homosexuality: Cardiac responses of low and high homonegative males. Journal of Homosexuality Special Issue: Homophobia: An overview, 10 (1-2), 53-67.

Van de Ven, P., Bornholt, L., Bailey, M. (1996). Measuring cognitive, affective, and behavioral components of homophobic reaction. Archives of Sexual Behavior, 25, 155-179.

Vanman, E. J., Paul, B. Y., Ito, T. A., \& Miller, N. (1997). The modern face of prejudice and structural features that moderate the effect of cooperation and affect. Journal of Personality and Social Psychology, 73, 941-959.

Weinberg, G. (1973). Society and the Healthy Homosexual. Garden City, NY: Anchor Books.

Wittenbrink, B., Judd, C. M., \& Park, B. (1997). Evidence for racial prejudice at the implicit level and its relationship with questionnaire measures. Journal of Personality \& Social Psychology, 72, 262-274.

Yang, A. (1998). From wrongs to rights: Public opinion on gay and lesbian Americans moves toward equality. Washington, DC: National Gay and Lesbian Task Force Policy Institute. 
Copyright of Basic \& Applied Social Psychology is the property of Lawrence Erlbaum Associates and its content may not be copied or emailed to multiple sites or posted to a listserv without the copyright holder's express written permission. However, users may print, download, or email articles for individual use. 